\title{
ELEGTROENCEPHALOGRAPHIG STUDIES ON THIAMINE DERIVATIVES IN THE RABBIT
}

\author{
YOSHIHIRO MATSUDA, IZURU MATSUOKA, \\ SHUJI TAKAORI AND KIRO SHIMAMOTO \\ Department of Pharmacology, Faculty of Medicine, Kyoto University, Sakyo-ku, Kyoto
}

Received for publication October 26, 1966

It has been demonstrated by several investigators that the cardiac effects of alkyldisulfide derivatives of thiamine are considerably different from those of thiamine HCl. Misu et al. (1) in this laboratory have observed the effects of thiamine derivatives on the spontaneous contraction and transmembrane potentials of the isolated rabbit's atria. Thiamine tetrahydrofurfuryl disulfide (TTFD) prolonged the repolarization phase of the action potential and antagonized the shortening of the same phase caused by hypoxia. Furthermore, TTFD prolonged the time length required to abolish the spontaneous contraction of the atria induced by hypoxia, but thiamine $\mathrm{HCl}$ did not so. The positive inotropic effect and prolongation of the repolarization time in the isolated guinea-pig's atria have been confirmed by Nakazawa and Ueno (2) and Kanno (3) in TTFD and thiamine propyldisulfide but not in thiamine $\mathrm{HCl}$.

The blocking effects of thiamine derivatives on the neuro-muscular junction (4-6) and the sympathetic ganglion $(7,8)$ have been reported. Thiamine was also described to inhibit the activity of cholinesterase (9). These findings indicate the possibility that thiamine derivatives, especially the alkyldisulfides, exert cholinergic excitement in the central nervous system. The present report deals with effects of thiamine derivatives on the spontaneous EEG of rabbits, when these drugs are administered into the ear marginal vein, common carotid artery or lateral ventricle.

\section{METHODS}

About 60 male albino rabbits weighing 2.0 to $3.0 \mathrm{~kg}$ were used. After insertion of the tracheal cannula the head of animal was fixed on the stereotaxic instrument (TodaiNoken type) under ether anesthesia. The suitable sites of the exposed skull were trepanned for recording the cortical and hippocampal EEG and for stimulating the midbrain reticular formation or thalamus. The sites of the subcortical structures were determined according to the topographic map of Sawyer et al. (10): dorsal hippocampus (F: - 6, L: 6, H: 5), midbrain reticular formation (F: -9, L: 2, H: - 1.5) and Nucleus centre médian of thalamus (F: $-5, \mathrm{~L}: 2, \mathrm{H}:-1)$. The cortical EEG was recorded 
epidurally from the motor cortex using monopolar or bipolar silver ball electrodes, and the hippocampal EEG was recorded monopolarly by means of insulated silver electrode. The indifferent electrode was placed on the frontal cranium. Bipolar steel stimulation electrodes were insulated except the tips and the interpolar distance was about 2 $\mathrm{mm}$. Square wave stimuli, $300 \mathrm{cps}$ and $1 \mathrm{msec}$ in width, were used for stimulation to obtain the reticular arousal response. The same wave stimuli, $8 \mathrm{cps}$ and $1 \mathrm{msec}$ in width, were employed for stimulation of the thalamus to obtain the recruiting response. Electroencephalograph (San'ei Sokki, Type EG-129), EEG analyzer (San'ei Sokki, Type EA-101) and electronic stimulator (Nihon Koden, Type MSE-3) were used.

The experiments were performed in the sound-proof room at the temperature of 22 $\pm 2^{\circ} \mathrm{C}$ and were started 3 hours after the termination of the surgical procedures and ether inhalation.

The drugs used were thiamine hydrochloride (thiamine $\mathrm{HCl}$ ), thiamine propyldisulfide hydrochloride (TPD) and thiamine-8-(methyl-6-acetyl-dihydrothioctate) disulfide hydrochloride (TATD). The drugs were dissolved in distilled water and were injected into the ear marginal vein, common carotid artery or lateral ventricle. For the intraventricular injection the long steel tube was stereotaxically inserted and was fixed on the skull with dental cement. The volume of the drug solution was adjusted to $0.1 \mathrm{ml}$.

\section{RESULTS}

\section{Classification of the spontaneous EEG in unanesthetized rabbits}

The spontaneous EEG recorded from the motor cortex and hippocampus of unanesthetized rabbits was classified into following 5 types:

\section{1) Completely arousal pattern}

The cortical EEG showed low-voltage fast waves $(20-40 \mu \mathrm{V}, 30-55 \mathrm{cps})$, and the hippocampal EEG consisted of relatively high-voltage and regular slow waves $(100-150 \mu \mathrm{V}$, 4-6 cps). However, the cortical EEG recorded monopolarly was superimposed regular slow waves $(30-60 \mu \mathrm{V}, 4-6 \mathrm{cps})$ which synchronized with the hippocampal regular arousal pattern.

\section{2) Completely resting pattern}

The cortical EEG showed high-voltage slow waves $(100-200 \mu \mathrm{V}, 1-4 \mathrm{cps})$ with or without spindle bursts $(50-150 \mu \mathrm{V}, 8-15 \mathrm{cps})$. The hippocampal EEG consisted of highvoltage and irregular slow waves $(100-200 \mu \mathrm{V}, 1-4 \mathrm{cps})$ intermingled with relatively lowvoltage waves $(30-60 \mu \mathrm{V}, 10-15 \mathrm{cps})$.

\section{3) Partially arousal pattern}

The cortical EEG showed mainly low-voltage fast waves and the hippocampal EEG consisted of synchronized slow waves of 4 to $6 \mathrm{cps}$ in frequency. Partially, the former was intermingled with slow or spindle waves and the latter was mixed with irregular slow (2-4 cps) or intermediate frequency $(10-15 \mathrm{cps})$ waves. 
to exhibit the desynchronized irregular pattern was also classified into this group, when the cortical EEG showed the completely arousal pattern.

\section{4) Partially resting pattern}

The cortical EEG showed mainly high-voltage slow waves and the hippocampal EEG consisted of irregular slow waves. However, the former was partially intermingled with low-voltage fast waves and the latter sometimes mixed with relatively synchronized pattern.

\section{Mixed pattern}

The cortical and hippocampal EEG showed the alternative appearance of the resting and arousal patterns.

\section{Effects of thiamine derivatives \\ 1) Thiamine propyldisulfide (TPD)}

Spontaneous behavior and EEG were not modified by the intravenous injection of TPD in the doses below $5 \mathrm{mg} / \mathrm{kg}$ in the rabbit. However, the animal received 10 to 20 $\mathrm{mg} / \mathrm{kg}$ of TPD showed the manifestation of struggle, miosis and tachypnea immediately after the intravenous injection. These effects lasted only for about 30 seconds. Several minutes after the injection, motor excitement and hyperreactivity to the external stimuli were observed. The cortical EEG was altered into the low-voltage fast waves, and the high-

\section{$E E G \quad \begin{aligned} & \text { Integrated values } \\ & \text { of cortical }\end{aligned}$}

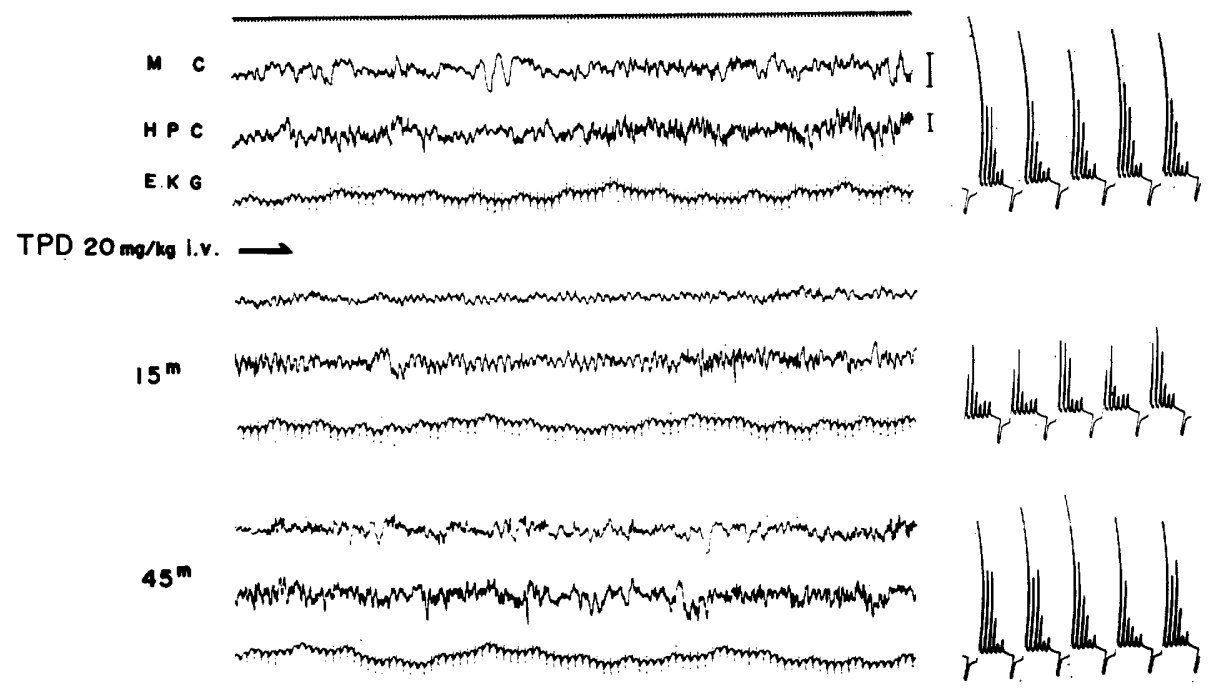

Fig. 1. Effect of intravenous injection of TPD on the spontaneous EEG. MC: Motor cortex, HPG : Hippocampus, EKG : Electrocardiogram. Calibration : Vertical bar, $100 \mu \mathrm{V}$; time scale, 0.1 second. Each integrated value represents 2-4, 4-8, 8-15, 15-30, 30-55 and 65-100 cps-band activities respectively, for 10 seconds. 
TABLE 1. Changes of the EEG pattern following intravenous injection of TPD, TATD and thiamine HCl.

\begin{tabular}{|c|c|c|c|c|c|c|c|c|}
\hline Drugs & Doses & $\begin{array}{c}\text { Rabbit } \\
\text { No. }\end{array}$ & Before & 5 & 10 & 15 & 30 & $60(\min )$ \\
\hline TPD & $20 \mathrm{mg} / \mathrm{kg}$ & $\begin{array}{r}1 \\
2 \\
3 \\
4 \\
5 \\
6 \\
7 \\
8 \\
9 \\
10 \\
11\end{array}$ & $\begin{array}{c}\mathbf{M} \\
\mathbf{M} \\
\mathrm{R} \\
\mathrm{R} \\
\mathrm{R} \\
\mathrm{R} \\
(\mathrm{A}) \\
\mathrm{R} \\
\mathrm{R} \\
\mathrm{R} \\
(\mathrm{R})\end{array}$ & $\begin{array}{c}\mathrm{M} \\
\mathrm{M} \\
\mathrm{A} \\
\mathrm{A} \\
\mathrm{A} \\
\mathrm{A} \\
\mathrm{A} \\
\mathrm{A} \\
\mathrm{R} \\
(\mathrm{R}) \\
(\mathrm{R})\end{array}$ & $\begin{array}{c}(\mathrm{A}) \\
(\mathrm{A}) \\
\mathrm{A} \\
\mathrm{A} \\
\mathrm{A} \\
\mathrm{A} \\
\mathrm{A} \\
\mathrm{A} \\
(\mathrm{R}) \\
(\mathrm{A}) \\
\mathrm{M}\end{array}$ & $\begin{array}{c}(\mathrm{A}) \\
(\mathrm{A}) \\
\mathrm{A} \\
\mathrm{A} \\
\mathrm{A} \\
\mathrm{A} \\
\mathrm{A} \\
\mathrm{A} \\
(\mathrm{R}) \\
\mathrm{A} \\
\mathrm{M}\end{array}$ & $\begin{array}{c}\mathrm{M} \\
(\mathrm{A}) \\
\mathrm{A} \\
(\mathrm{A}) \\
(\mathrm{A}) \\
\mathrm{A} \\
\mathrm{A} \\
(\mathrm{A}) \\
\mathrm{R} \\
\mathrm{R} \\
\mathrm{M}\end{array}$ & $\begin{array}{c}\mathbf{M} \\
\mathbf{M} \\
(\mathrm{A}) \\
(\mathrm{A}) \\
(\mathrm{A}) \\
\mathbf{A} \\
\mathbf{A} \\
\mathbf{M} \\
(\mathbf{R}) \\
\mathbf{M} \\
\mathbf{M}\end{array}$ \\
\hline \multirow[t]{2}{*}{ TATD } & $20 \mathrm{mg} / \mathrm{kg}$ & $\begin{array}{l}1 \\
2 \\
3 \\
4 \\
5 \\
6 \\
7\end{array}$ & $\begin{array}{c}(\mathbf{R}) \\
(\mathrm{A}) \\
\mathbf{M} \\
(\mathbf{R}) \\
(\mathrm{A}) \\
\mathbf{A} \\
\mathbf{M}\end{array}$ & $\begin{array}{l}(\mathrm{R}) \\
(\mathrm{R}) \\
(\mathrm{R}) \\
\mathrm{R} \\
\mathbf{M} \\
\mathrm{R} \\
\mathrm{M}\end{array}$ & $\begin{array}{c}(\mathbf{R}) \\
(\mathbf{R}) \\
\mathbf{M} \\
\mathbf{R} \\
\mathbf{M} \\
(\mathrm{R}) \\
\mathbf{M}\end{array}$ & $\begin{array}{c}(\mathrm{R}) \\
(\mathrm{A}) \\
\mathbf{M} \\
(\mathrm{R}) \\
\mathbf{M} \\
(\mathrm{A}) \\
\mathbf{M}\end{array}$ & $\begin{array}{c}\mathbf{M} \\
(\mathrm{A}) \\
\mathbf{M} \\
(\mathrm{R}) \\
(\mathrm{A}) \\
\mathrm{A} \\
\mathbf{M}\end{array}$ & $\begin{array}{c}(\mathrm{R}) \\
(\mathrm{A}) \\
\mathbf{M} \\
(\mathrm{R}) \\
(\mathrm{A}) \\
\mathrm{A} \\
\mathbf{M}\end{array}$ \\
\hline & $50 \mathrm{mg} / \mathrm{kg}$ & $\begin{array}{r}8 \\
9 \\
10 \\
11 \\
12 \\
13\end{array}$ & $\begin{array}{c}\mathbf{R} \\
\mathbf{M} \\
\mathbf{A} \\
(\mathbf{R}) \\
(\mathrm{R}) \\
(\mathrm{R})\end{array}$ & $\begin{array}{c}\mathrm{R} \\
(\mathrm{R}) \\
\mathrm{R} \\
\mathrm{M} \\
\mathrm{R} \\
\mathrm{R}\end{array}$ & $\begin{array}{c}\mathbf{R} \\
\mathbf{R} \\
\mathbf{R} \\
\mathbf{M} \\
(\mathbf{R}) \\
(\mathbf{R})\end{array}$ & $\begin{array}{c}\mathrm{R} \\
\mathrm{R} \\
\mathrm{A} \\
\mathrm{M} \\
(\mathrm{A}) \\
\mathrm{M}\end{array}$ & $\begin{array}{c}\mathrm{R} \\
(\mathrm{R}) \\
\mathrm{A} \\
\mathrm{M} \\
(\mathrm{A}) \\
(\mathrm{A})\end{array}$ & $\begin{array}{c}\mathrm{A} \\
\mathrm{M} \\
\mathrm{A} \\
\mathrm{M} \\
(\mathrm{A}) \\
(\mathrm{A})\end{array}$ \\
\hline Thiamine $\mathrm{HCl}$ & $20 \mathrm{mg} / \mathrm{kg}$ & $\begin{array}{l}1 \\
2 \\
3 \\
4 \\
5\end{array}$ & $\begin{array}{l}(\mathrm{R}) \\
\mathbf{M} \\
(\mathrm{R}) \\
(\mathrm{R}) \\
(\mathrm{R})\end{array}$ & $\begin{array}{c}(\mathrm{R}) \\
\mathrm{M} \\
(\mathrm{R}) \\
\mathbf{M} \\
\mathrm{R}\end{array}$ & $\begin{array}{c}(\mathbf{R}) \\
\mathbf{M} \\
(\mathbf{R}) \\
(\mathbf{R}) \\
(\mathbf{R})\end{array}$ & $\begin{array}{c}\mathbf{R} \\
\mathbf{M} \\
(\mathbf{R}) \\
\mathbf{M} \\
(\mathbf{R})\end{array}$ & $\begin{array}{l}(\mathrm{R}) \\
\mathrm{M} \\
\mathrm{M} \\
\mathrm{M} \\
\mathrm{M}\end{array}$ & $\begin{array}{l}(\mathbf{R}) \\
\mathbf{M} \\
(\mathbf{R}) \\
(\mathbf{R}) \\
(\mathbf{R})\end{array}$ \\
\hline
\end{tabular}

A : Completely arousal pattern, (A) : Partially arousal pattern, $\mathrm{R}$ : Completely resting pattern, (R) : Partially resting pattern, M : Mixed pattern.

voltage slow waves and spindle bursts disappeared. The hippocampal EEG showed an increase in synchronized regular pattern (Fig. 1). Such arousal pattern of the EEG was found in 9 of 11 animals and lasted for 30 to 60 minutes (Table 1).

During the manifestation of the arousal pattern of spontaneous EEG caused by the intravenous injection of $20 \mathrm{mg} / \mathrm{kg}$ of TPD, the stimulation thresholds for the reticular arousal response and recruiting response were not significantly changed (Fig. 2). However, the recruiting response was slightly reduced in amplitude by TPD (Fig. 3).

The intracarotid injection of TPD in the doses below $0.5 \mathrm{mg} / \mathrm{kg}$ did not affect the spontaneous EEG. The arousal pattern of the cortical and hippocampal EEG appeared several minutes after the intracarotid injection of $2 \mathrm{mg} / \mathrm{kg}$ of TPD and lasted for 15 to 20 minutes. The similar arousal pattern was observed about 5 minutes after the intraventricular administration of 0.5 to $1 \mathrm{mg} / \mathrm{kg}$ of TPD. However, stimulation thresholds for the reticular arousal response and recruiting response were not changed by TPD.

2) Thiamine-8-(methyl-6-acetyl-dihydrothioctate) disulfide (TATD)

The spontaneous EEG changed to the resting pattern immediately after the intravenous 


\section{E E G Arousal Response \\ (Stim. : Reticular Formation)}

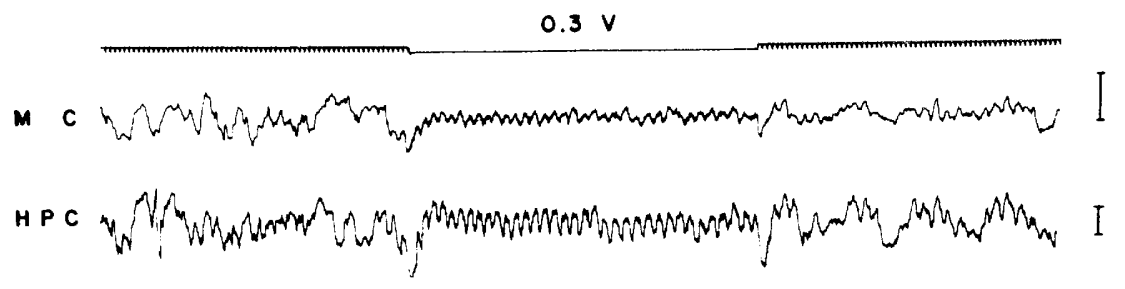

TPD $20 \mathrm{mg} / \mathrm{kg}$ i.v.

$0.3 \mathrm{~V}$

$15^{m}$

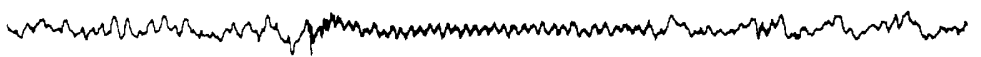

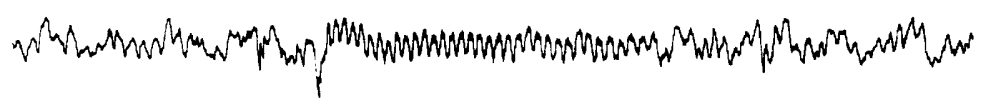

FIG. 2. Effect of TPD on the reticular arousal response induced by electrical stimulation of the midbrain reticular formation $(300 \mathrm{cps}, 1 \mathrm{msec}, 7 \mathrm{~seconds})$.

Abbreviation and calibration : see Fig. 1.

\section{Recruiting Response}

(Stim. : Nucl. cent. méd.)

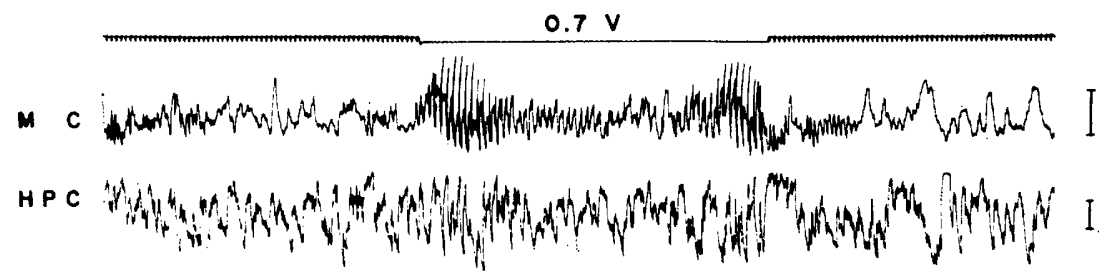

TPD $20 \mathrm{mg} / \mathrm{kg}$ I.v. $\longrightarrow$

$0.7 v$

$15^{m}$
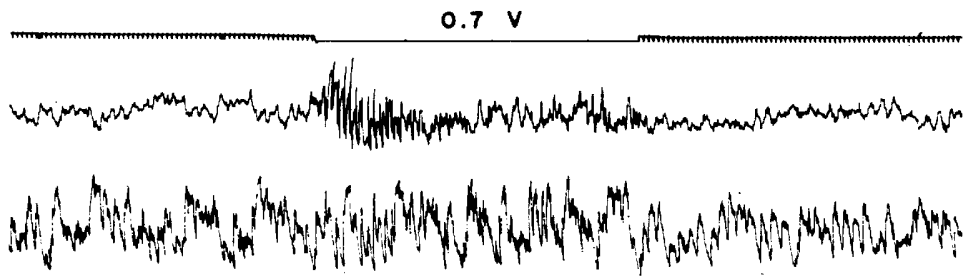

Fig. 3. Effect of TPD on the recruiting response induced by electrical stimulation of the Nucleus centre médian of thalamus ( $8 \mathrm{cps}, 1 \mathrm{msec}, 7$ seconds).

Abbreviation and calibration : see Fig. 1.

injection of $20 \mathrm{mg} / \mathrm{kg}$ of TATD in 5 of 7 animals. The cortical EEG altered into the highvoltage slow waves with spindle bursts and the hippocampal EEG showed the high-voltage and irregular slow waves. The resting pattern lasted for 10 to 15 minutes. The rabbits 
LMC

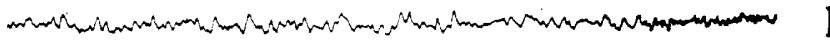

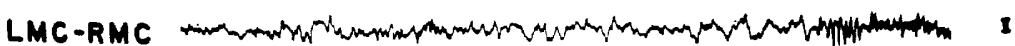

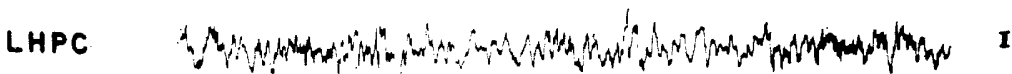

EKG

TATD $50 \mathrm{mg} / \mathrm{kg} \mathrm{l.v.} \longrightarrow$

$5^{m}$
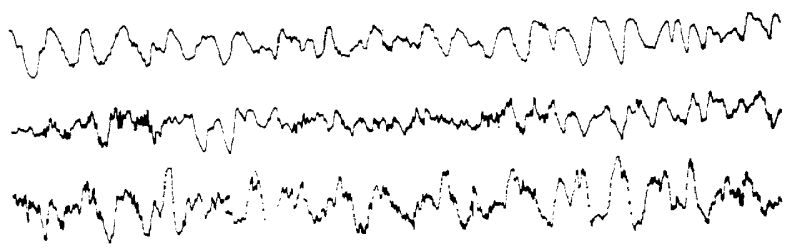

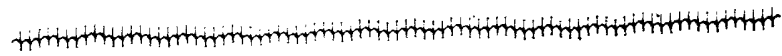

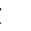


LMC-RMC

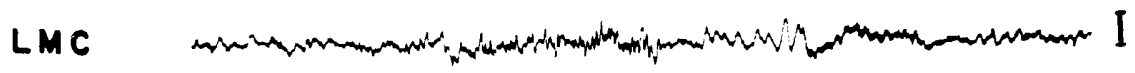

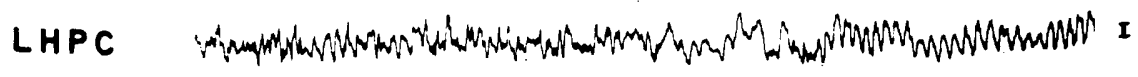

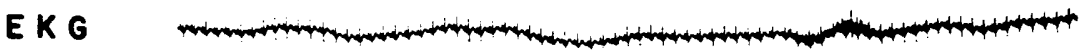

TATD $1.0 \mathrm{mg} / \mathrm{kg}$ i.vent.

$10 \mathrm{~m}$

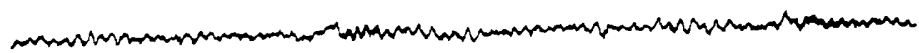

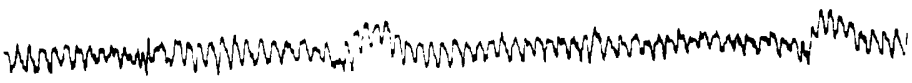

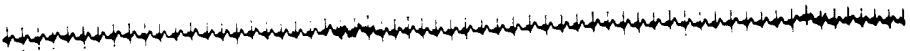

$70^{m}$
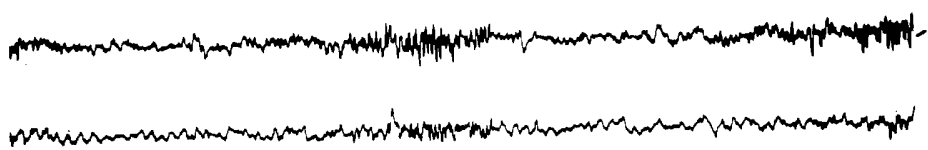

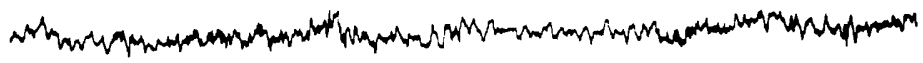

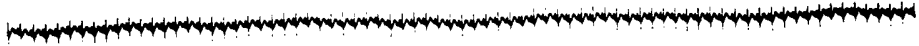

FIG. 5. Effect of intraventricular injection of TATD on the spontaneous EEG.

Abbreviation and calibration : see Figs. 1 and 4.

bradycardia were found immediately after the injection but these effects disappeared rapidly. One animal which showed the resting pattern over 30 minutes by $50 \mathrm{mg} / \mathrm{kg}$ of TATD exhibited miosis still 45 minutes after the injection. The stimulation thresholds for the reticular arousal response and recruiting response were not changed by the doses of TATD, but the amplitude of the recruiting response was slightly reduced in some of the animals. The intracarotid injection of 2 to $5 \mathrm{mg} / \mathrm{kg}$ of TATD did not modify the spontaneous EEG.

On the other hand, the intraventricular administration of $1 \mathrm{mg} / \mathrm{kg}$ of TATD produced the manifestation of the arousal pattern in the cortical and hippocampal EEG, and the effects appeared from 2 to 5 minutes after the injection and lasted for 60 to 80 minutes (Fig. 5). 
In accord with the appearance of the arousal pattern, the animals showed motor excitement, hyperreactivity to the external stimuli, tachypnea and slight mydriasis. The intraventricular administration of TATD did not change the thresholds for the reticular arousal response and recruiting response.

\section{3) Thiamine $\mathrm{HCl}$}

The intravenous injection of $20 \mathrm{mg} / \mathrm{kg}$ and the intracarotid injection of 2 to $5 \mathrm{mg} / \mathrm{kg}$ of thiamine $\mathrm{HCl}$ did not affect spontaneous behaviors, EEG and thresholds for the reticular arousal response and recruiting response. However, the intraventricular administration of $0.5 \mathrm{mg} / \mathrm{kg}$ of thiamine $\mathrm{HCl}$ produced motor excitement and mydriasis associated with the manifestation of the arousal pattern of EEG. Immediately after the intraventricular injection of $1 \mathrm{mg} / \mathrm{kg}$, the animals showed bradycardia, motor excitement, irregular respiration and defecation. The spontaneous EEG changed to the completely arousal pattern. The motor excitement and mydriasis were still found 30 minutes after the injection, and the arousal pattern lasted over 2 hours. However, the stimulation thresholds for the reticular arousal response and recruiting response were not modified.

\section{DISCUSSION}

The demonstration of the positive inotropic effects of thiamine alkyldisulfides in the isolated heart (1-3) has presented a discussion whether the effects derive from thiamine molecule or the disulfide structure on the excitable cells. The present experiments are also a challenge to some unknown mechanism of the action of the disulfide structure.

The intravenous injection of 10 to $20 \mathrm{mg} / \mathrm{kg}$ and the intracarotid injection of $2 \mathrm{mg} / \mathrm{kg}$ of TPD produced the arousal pattern in the cortical and hippocampal EEG associated with the manifestation of motor excitement and hyperreactivity to the external stimuli. On the other hand, the spontaneous EEG showed the resting pattern immediately after the intravenous injection of 20 to $50 \mathrm{mg} / \mathrm{kg}$ of TATD. The resting pattern caused by TATD altered into the arousal pattern 15 to 30 minutes after the injection in some of the animals. The intravenous and intracarotid injection of thiamine $\mathrm{HCl}$ did not affect the spontaneous behavior and EEG.

In contrast to considerable difference in the EEG effects between TPD, TATD and thiamine $\mathrm{HCl}$ injected intravenously, the intraventricular administration of these drugs always produced the arousal pattern of the cortical and hippocampal EEG. The dissociation in the EEG effects between the systemic and intraventricular administration may relate with easiness in the passage through the blood-brain barrier. Sasakawa et al. (11) have reported that the amount of TPD distributed in the brain are three times more than that of thiamine $\mathrm{HCl}$ when both drugs are administered intravenously.

The possibility of thiamine derivatives as a cholinesterase inhibitor (9) merits some considerations, because physostigmine, a cholinesterase inhibitor, produces the arousal pattern in the cortical and hippocampal EEG (12). The increasing effects of TPD on the brain blood flow (13) may also make a contribution of the arousal change of the 
EEG. The exact mechanism of the dissociation in the central effects between thiamine $\mathrm{HCl}$ and its derivatives should be settled in further studies.

In the present experiments, relatively higher doses of TPD, TATD and thiamine $\mathrm{HCl}$ did not change the stimulation thresholds for the reticular arousal response and recruiting response, though they reduced slightly the amplitude of the recruiting response in some animals. These results suggest that the thiamine derivatives differ from methamphetamine in the central action. In this respect, the demonstration by Minami et al. (14) that the intravenous injection of $1 \mathrm{mg} / \mathrm{kg}$ of TTFD depressed the reticular arousal response should be reinvestigated in respect to the central action and dosage of thiamine derivatives.

\section{SUMMARY}

The effects of thiamine $\mathrm{HCl}$ and its disulfide derivatives such as TPD and TATD on the spontaneous EEG in the motor cortex and hippocampus, reticular arousal response and recruiting response were studied in the rabbits.

1. TPD in the intravenous doses of 10 to $20 \mathrm{mg} / \mathrm{kg}$, intracarotid dose of $2 \mathrm{mg} / \mathrm{kg}$ and intraventricular doses of 0.5 to $1 \mathrm{mg} / \mathrm{kg}$ produced the arousal pattern of EEG and behavioral excitement.

2. The cortical and hippocampal EEG altered into the resting pattern immediately after the intravenous injection of TATD. Thereafter, the spontaneous EEG was restored to the previous level in most of the rabbits, but it was changed to the arousal pattern in some of the animals. The intraventricular administration of TATD resulted in the arousal pattern of the EEG.

3. The intravenous and intracarotid injection of thiamine $\mathrm{HCl}$ did not affect the cortical and hippocampal EEG, while the intraventricular administration produced the arousal pattern of the EEG associated with behavioral excitement.

4. The stimulation thresholds for the reticular arousal response and recruiting response were not changed by TPD, TATD and thiamine HCl. However, the amplitude of the recruiting response was slightly reduced by these drugs.

5. The role of the disulfide structure of thiamine derivatives on the central action is discussed.

\section{REFERENCES}

1) Misu, Y., Takaori, S. And Shimamoto, K.: This Journal 15, 257 (1965)

2) Nakazawa, Y. and Ueno, A.: Ibid. 15, 10 (1965)

3) Kanno, M.: Archs int. Pharmacodyn. Thér. 157, 280 (1965)

4) Cheymol, J., Bourillet, F., Levassort, C. and Kerp, L.: Ibid. 111, 36 (1957)

5) Ngai, S.H., Ginsburg, S. and Katz, R.L.: Biochem. Pharmac. 7, 256 (1961)

6) Ueda, M.: This Journal 16, 39 (1966)

7) Yамамото, I.: Ibid. 13, 240 (1963)

8) Yamamoto, I., Otori, K., Kojima, S. And Mizoguchi, K.: Ibid. 15, 298 (1965)

9) Drilt, V.A.: Pharmacology in Modicine, p. 885, McGraw-Hill Book Co., New York (1958)

10) SAwyer, C.H., Everett, J.M. And Green, J.P.: J. comp. Neurol. 101, 801 (1954) 
11) Sasakawa, S., Itokawa, Y. ANd Ikeda, K.: Vitamin 32, 193 (1965)

12) Killam, E.K.: Pharmac. Rev. 14, 175 (1962)

13) Morimitsu, H.: Igaku to seibutsugaku 68, 136 (1964) (In Japanese)

14) Minami, Y. and Narto, H.: The XVII Annual Meeting of Japanese Gynecological Society (1965) 